\title{
ASSOCIATION BETWEEN MENTAL HEALTH SCREENING BY SELF-REPORT QUESTIONNAIRE AND INSOMNIA IN MEDICAL STUDENTS
}

\author{
Maria Paz Loayza H. ${ }^{1}$, Talles S. Ponte ${ }^{2}$, Clarissa G. Carvalho' ${ }^{2}$, Michell R. Pedrotti², \\ Paula V. Nunes², Camila M. Souza², Camila B. Zanette², Sara Voltolini², Marcia L. F. Chaves ${ }^{3}$
}

\begin{abstract}
Epidemiological research points to the high prevalence of psychiatric disorders among insomniacs. We carried out a cross-sectional study with medical students with the aim of evaluating the association between insomnia and suspicion of psychiatric disorder; 302 medical students were included (184 males and 118 females; mean age $=20.47 \pm 1.89$ years). The main association was tested by logistic regression analysis. The overall prevalence of positivity in a screening test for psychiatric disorder was $22.19 \%$; and of insomnia, 28.15\%. Difficulty initiating sleep $(O R=3.45)$, difficulty maintaining sleep $(O R=7.61)$, falling asleep later $(O R=1.99)$ and waking up earlier $(O R=1.91)$ were associated with suspicion of psychiatric disorder. As a group, the variables difficulty initiating sleep, difficulty maintaining sleep, falling asleep after $11 \mathrm{pm}$, and waking up before 6 am presented an odds ratio of 5.96 for positivity in the screening for psychiatric disorder. Furthermore, difficulty maintaining sleep $(\mathrm{OR}=2.24)$ was associated with "being female," and falling asleep later $(\mathrm{OR}=0.43)$ was associated with "being male". These results underscore the importance of determining in what cases difficulty sleeping may have severe clinical repercussions or affect performance.
\end{abstract}

KEY WORDS: insomnia, psychiatric disorder, sleep, gender.

\begin{abstract}
Associação entre insônia e screening para doença mental pelo SRQ-20 em estudantes de medicina
RESUMO - Estudos epidemiológicos têm mostrado alta prevalência de transtorno psiquiátrico em pessoas com insônia. Realizamos estudo transversal em amostra de estudantes de medicina, com o objetivo de avaliar a associação entre insônia e positividade na triagem para transtorno psiquiátrico; 302 estudantes foram incluídos (184 homens e 118 mulheres; média da idade $=20.47 \pm 1,89$ anos). A associação foi testada através da análise de regressão logística. A prevalência de teste positivo na triagem para transtorno psiquiátrico foi $22,19 \%$; e de insônia, $28,15 \%$. Dificuldade para iniciar o sono $(O R=3,45)$, dificuldade para manter o sono $(\mathrm{OR}=7,61)$, dormir tarde $(\mathrm{OR}=1,99)$ e levantar cedo $(\mathrm{OR}=1,91)$ foram as variáveis associadas à possibilidade de transtorno psiquiátrico. Quando consideradas em conjunto, as variáveis "dificuldade em iniciar o sono", "dificuldade em manter o sono", "dormir após 23 h" e "acordar antes das 6 h" apresentaram razão de chance de 5,96 para positividade na triagem para transtorno psiquiátrico. Além disso, dificuldade em manter o sono $(O R=2,24)$ foi associada ao sexo feminino; e dormir tarde $(O R=0,43)$, ao sexo masculino. Esses resultados enfatizam a importância de determinar em que caso a dificuldade com o sono pode ter repercussões clínicas severas ou afetar o desempenho.
\end{abstract}

PALAVRAS-CHAVE: insônia, transtorno psiquiátrico, sono, gênero.

Insomnia is a broad concept that has been described as a symptom, a complaint, a disturbance and/or a consequence of other clinical problems ${ }^{1}$. Insomnia may have a deep social impact both in terms of direct and indirect costs. Direct costs involve diagnostic testing, treatment, and medical visits, among others, whereas indirect costs include morbidity-related medical expenses, decreased productivity at work, and automobile accidents ${ }^{2,3}$.
Previous epidemiological research indicates that the prevalence of all psychiatric disorders is higher in individuals affected by insomnia. The risk for depression has been shown to be approximately four times higher in insomniacs ${ }^{4}$. In addition, the results of prospective studies suggest that insomnia complaints may be an early marker of psychiatric disorders such as depression, anxiety, and alcohol abuse ${ }^{4,5}$.

Some specific groups seem to be more affected

\footnotetext{
Study developed at the Graduate Program in Internal Medicine - Behavioral Sciences, Universidade Federal do Rio Grande do Sul (UFRS), Porto Alegre RS, Brazil: ${ }^{1} \mathrm{MD}$, MSc, Psychiatrist; ${ }^{2}$ Undergraduate student, UFRS; ${ }^{3} \mathrm{MD}$, PhD, Neurologist, Advisor, Graduate Program in Internal Medicine - Behavioral Sciences, UFRS.
}

Received 5 September 2000, received in final form 16 november 2000. Accepted 20 november 2000. 
by insomnia, for example women, shift schedule workers, and those who do not get the right amount of sleep ${ }^{6,7}$. Among these groups, medical students have received special attention ${ }^{7,8}$. Daugherty and Baldwin ${ }^{8}$ found that sleep deprivation is a part of both undergraduate medical education and the initial stages of residency training. In the present study, we assessed a sample of medical students with the aim of evaluating the association between insomnia and positivity in a screening test for psychiatric disorders.

\section{METHOD}

The present study was designed as a cross-sectional study. The outcome measure was the result of a screening test for psychiatric disorders. The study protocol was approved by the Ethics Committee at the institution in which the work was carried out. All study participants signed an informed consent form.

Subjects completed a questionnaire for collection of data regarding demographic characteristics and sleep habits, and a screening instrument for psychiatric disorders (Self-Reporting Questionnaire, SRQ-20) ${ }^{9,10}$.

The SRQ-20 addresses four factors (somatization, depressive/anxious moods and depressive thoughts) which are known as minor psychiatric disorders ${ }^{10}$. A Brazilian Portuguese version of the SRQ-20 has been validated, and the cut-off points for the presence of non-psychotic morbidity were established as $\leq 8$ for women and $\leq 6$ for men. The diagnostic values of SRQ were sensitivity $83 \%$ and specificity $80 \%{ }^{9}$.

The following questions refer to sleep habits and were used in the study:

1. Do you have difficulty falling asleep at night? (Difficulty initiating sleep; InitS)

2. Do you wake up during the night after you have gone to sleep? (Difficulty maintaining sleep; MaintS)

3. Do you wake up too early in the morning and have difficulty getting back to sleep? (Early morning awakening; EMA)

4. Do you feel tired in the first hour after waking up? (Tiredness)

5. What is your usual time to wake up? (Waking up)

6. What is your usual time to fall asleep? (Fall asleep)

The first three questions were yes or no questions associated with insomnia. As defined by Kim ${ }^{11}$, insomnia is present when affirmative answers are given to any of these three questions.

A total of 302 medical students answered the questionnaires. Sixty-seven tested positive for psychiatric disorders (SRQ+) and 235 tested negative (SRQ-). Exclusion criteria were working night duty, self report of past or current history of psychopathology, as well as medical condition and use of drugs known to influence sleep. Individuals who refused to participate after two attempts or who abandoned the study before having completed half the questionnaire were classified as a "refusal to participate." Total loss was 3.64\%. The data were collected by 5 research assistants who received six half days of training with the help of role-playing. The interviewers and the subjects were blinded to the objective of the study.

Statistical analysis

To analyze the continuous variables "usual time to wake up" and "usual time to fall asleep" as categorical variables, the first quartile (6 am) and the last quartile (11 pm) were used, respectively.

Continuous variables were analyzed using the independent Student's $t$ test. Univariate analysis and the $\chi^{2}$ test (Mantel-Haensel with Yates correction) were used to assess differences in the proportions of the studied variables $^{12}$. Logistic regression analyses were carried out in the course of assessing the effects of confounding variables and of reporting an association between positivity in SRQ and sleep habits, and positivity in SRQ and gen$\operatorname{der}^{13,14}$.

Variables showing a significant association with psychiatric disorders (SRQ + ) were included in a multivariate logistic regression following the stepwise backward procedure $^{15}$. A $p$ value of less than 0.20 was required for a factor to be retained in the analysis ${ }^{13}$. Values were considered significant when the type-I error $(p)$ was below or equal to 0.05 . All procedures were carried out using the Statistical Package for the Social Sciences (SPSS/PC+) and the EPI-INFO 6.4 software ${ }^{16}$.

\section{RESULTS}

Three hundred and two students participated in the study (184 males, 118 females). Nine percent of the medical students had a paying job. The mean \pm sd age was $20.47 \pm 1.89$ years. The overall prevalence of SRQ+ in the study was $22.19 \%$ (67), and of insomnia, $28.15 \%$ (85). The prevalence of InitS was $17.22 \%$ (52); MaintS, 9.6\% (29); EMA, 15.23\% (46); tiredness, 51.33\% (155); falling asleep after $11 \mathrm{PM}$, $24.50 \%$ (74); and waking up before 6 AM, 37.42\% (113). Age was not different between the SRQ + and SRQ- groups $(t=0.78 ; p=0.44)$.

The association between insomnia and a positive $S R Q$ was significant $(O R=2.97)$. The association of the positivity in the SRQ with other sleep habits variables was also submitted to the $\chi^{2}$ test (MantelHaensel with Yates correction). The variables that showed association were InitS (OR=3.05), MaintS $(O R=3.73)$, EMA $(O R=2.54)$, tiredness $(O R=1.94)$ and waking up early $(O R=1.53)$. Falling asleep late and having a job (Table1) did not show significant associations.

The association between the SRQ classification and sleep habit variables was analyzed by logistic regression analysis (Table 2 ). It revealed that InitS $(O R=3.45)$, MaintS $(O R=7.61)$, falling asleep later 
Table 1. Univariate analysis of the association between sleep habits and positivity in a screen test for psychiatric disorder (SRQ+) $(n=302)$.

\begin{tabular}{|c|c|c|c|c|c|c|}
\hline \multirow[t]{2}{*}{ Variable } & \multirow[t]{2}{*}{ Categories } & \multicolumn{2}{|c|}{ SRQ } & \multirow[t]{2}{*}{$p$ value } & \multirow[t]{2}{*}{ Odds Ratio } & \multirow[t]{2}{*}{$95 \% \mathrm{Cl}$} \\
\hline & & Positive $\mathrm{N}=67$ & Negative $\mathrm{N}=235$ & & & \\
\hline \multirow[t]{2}{*}{ Insomnia } & Yes $(n=85)$ & 36 & 49 & 0.00 & 2.97 & $1.97-4.47$ \\
\hline & No $(n=217)$ & 31 & 186 & & & \\
\hline Difficulty & Yes $(n=52)$ & 26 & 26 & 0.00 & 3.05 & $2.06-4.5$ \\
\hline Initiating & No $(n=250)$ & 41 & 209 & & & \\
\hline \multicolumn{7}{|l|}{ Sleep } \\
\hline Difficulty & Yes $(n=29)$ & 19 & 10 & 0.00 & 3.73 & $2.58-5.39$ \\
\hline Maintaining & No $(n=273)$ & 48 & 228 & & & \\
\hline \multicolumn{7}{|l|}{ Sleep } \\
\hline \multirow[t]{2}{*}{ EMA } & Yes $(n=46)$ & 21 & 25 & 0.00 & 2.54 & $1.69-3.83$ \\
\hline & No $(n=256)$ & 46 & 210 & & & \\
\hline \multirow[t]{2}{*}{ Tiredness } & Yes $(n=155)$ & 45 & 110 & 0.00 & 1.94 & $1.23-3.06$ \\
\hline & No $(n=147)$ & 22 & 125 & & & \\
\hline \multirow[t]{2}{*}{ Fall asleep } & After 11 p.m. $(n=74)$ & 22 & 52 & 0.07 & 1.51 & $0.97-2.33$ \\
\hline & Before 11 p.m. $(n=228)$ & 45 & 183 & & & \\
\hline \multirow[t]{2}{*}{ Wake up } & Before 6 am $(n=113)$ & 32 & 81 & 0.05 & 1.53 & $1.01-2.33$ \\
\hline & After 6 am $(n=189)$ & 35 & 154 & & & \\
\hline \multirow[t]{2}{*}{ Employed } & Yes $(n=30)$ & 6 & 24 & 0.76 & 0.89 & $0.42-1.25$ \\
\hline & No $(n=272)$ & 61 & 211 & & & \\
\hline
\end{tabular}

Table 2. Results of stepwise backward logistic regression analysis: association between sleep habits and positivity in a screen test for psychiatric disorder.

\begin{tabular}{|c|c|c|c|c|c|c|}
\hline & Beta & S.E. & $p$ value & $\mathrm{R}$ & Odds Ratio & $95 \% \mathrm{Cl}$ \\
\hline \multicolumn{7}{|c|}{ Variable in the equation } \\
\hline InitS & 1.238 & 0.357 & 0.00 & 0.177 & 3.45 & $1.71-6.94$ \\
\hline MaintS & 2.029 & 0.462 & 0.00 & 0.233 & 7.61 & $3.08-18.81$ \\
\hline Fall asleep late & 0.691 & 0.339 & 0.04 & 0.082 & 2.00 & $1.03-3.88$ \\
\hline Wake up early & 0.649 & 0.311 & 0.04 & 0.086 & 1.91 & $1.04-3.52$ \\
\hline Constant & -2.343 & 0.590 & 0.00 & & & \\
\hline \multicolumn{7}{|c|}{ Variable not in the equation } \\
\hline EMA & & & 0.11 & 0.044 & & \\
\hline Tiredness & & & 0.10 & 0.047 & & \\
\hline
\end{tabular}

The partial correlation is expressed by the $R$ statistic, ranging from -1 to +1 .

$(O R=1.99)$ and waking up earlier $(O R=1.91)$ were associated with positive SRQ. The significant variables explained $80.13 \%$ of this outcome. The group of variables included in the equation determined an odds ratio of $5.96(95 \% \mathrm{Cl}=2.87-12.4)$.

The association between gender and insomnia was significant $(\mathrm{OR}=1.52$ ) (Table 3 ). The association of gender with positivity in the SRQ, sleep habits, and having a job was submitted to the $\chi^{2}$ test (Mantel-Haensel with Yates correction) (Table 3). The significant associations were with falling asleep later $(\mathrm{OR}=0.55)$, and MaintS $(\mathrm{OR}=1.58)$.

The association of gender with sleep habits and SRQ was analyzed by logistic regression (Table 4). It revealed that the presence of difficulty to maintain sleep (MaintS) was associated with "being female" 
Table 3. Univariate analysis for association of gender with sleep habits and positivity in a screen test for psychiatric disorder (SRQ+) $(n=302)$.

\begin{tabular}{|c|c|c|c|c|c|c|}
\hline \multirow[t]{2}{*}{ Variable } & \multirow[t]{2}{*}{ Categories } & \multicolumn{2}{|c|}{ Gender } & \multirow[t]{2}{*}{$p$ value } & \multirow[t]{2}{*}{ Odds Ratio } & \multirow[t]{2}{*}{$95 \% \mathrm{Cl}$} \\
\hline & & Female $n=118$ & Male $\mathrm{N}=184$ & & & \\
\hline \multirow[t]{2}{*}{ SRQ } & Yes $(+)(n=67)$ & 26 & 41 & 0.96 & 0.00 & $0.71-1.39$ \\
\hline & No $(-)(n=235)$ & 92 & 143 & & & \\
\hline \multirow[t]{2}{*}{ Insomnia } & Yes $(n=85)$ & 42 & 43 & 0.02 & 1.52 & $1.07-2.18$ \\
\hline & No $(n=217)$ & 76 & 141 & & & \\
\hline \multirow[t]{2}{*}{ InitS } & Yes $(n=52)$ & 26 & 26 & 0.08 & 1.36 & $0.99-1.86$ \\
\hline & No $(n=350)$ & 92 & 258 & & & \\
\hline \multirow[t]{2}{*}{ Maints } & Yes $(n=29)$ & 17 & 12 & 0.02 & 1.58 & $1.12-2.23$ \\
\hline & No $(n=273)$ & 101 & 172 & & & \\
\hline \multirow[t]{2}{*}{ EMA } & Yes $(n=46)$ & 23 & 23 & 0.09 & 1.34 & $0.97-1.87$ \\
\hline & No $(n=356)$ & 95 & 261 & & & \\
\hline \multirow[t]{2}{*}{ Tiredness } & Yes $(n=155)$ & 56 & 99 & 0.28 & 0.86 & $0.49-1.14$ \\
\hline & No $(n=147)$ & 62 & 85 & & & \\
\hline \multirow[t]{2}{*}{ Fall asleep } & After 11 p.m. $(n=74)$ & 18 & 56 & 0.00 & 0.55 & $0.36-0.85$ \\
\hline & Before 11 p.m. $(n=228)$ & 100 & 128 & & & \\
\hline \multirow[t]{2}{*}{ Wake up } & Before 6 am $(n=113)$ & 49 & 64 & 0.24 & 1.19 & $0.9-1.58$ \\
\hline & After 6 am $(n=189)$ & 69 & 120 & & & \\
\hline \multirow[t]{2}{*}{ Employed } & Yes $(n=30)$ & 11 & 19 & 0.78 & 0.93 & $0.57-1.53$ \\
\hline & No $(n=272)$ & 107 & 165 & & & \\
\hline
\end{tabular}

Table 4. Results of stepwise backward logistic regression analysis of the association between sex, sleep habits and positivity in a screen test for psychiatric disorder.

\begin{tabular}{|c|c|c|c|c|c|c|}
\hline & Beta & S.E & $p$ value & $\mathrm{R}$ & Odds Ratio & $95 \% \mathrm{Cl}$ \\
\hline \multicolumn{7}{|c|}{ Variable in the equation } \\
\hline MaintS & 0.804 & 0.40 & 0.05 & 0.070 & 2.24 & $1.02-4.89$ \\
\hline Sleep late & -0.850 & 0.30 & 0.01 & -0.120 & 0.43 & $0.24-077$ \\
\hline Constant & 0.382 & 0.46 & 0.41 & & & \\
\hline \multicolumn{7}{|c|}{ Variable not in the equation } \\
\hline InitS & & & 0.14 & 0.021 & & \\
\hline EMA & & & 0.70 & 0.000 & & \\
\hline Tiredness & & & 0.33 & 0.000 & & \\
\hline Wake up early & & & 0.17 & 0.000 & & \\
\hline SRQ & & & 0.62 & 0.000 & & \\
\hline
\end{tabular}

The partial correlation is expressed by the $R$ statistic, ranging from -1 to +1 .

$(\mathrm{OR}=2.24$; beta $=0.804)$. In turn, falling asleep later $(\mathrm{OR}=0.43)$ was related with "being male," as indicated by a negative beta coefficient $(-0.85)$.

\section{DISCUSSION}

The prevalence of positivity (22.19\%) in a screening test for psychiatric disorders in our sample did not differ significantly from the prevalence observed in studies with adolescents ${ }^{17}$ and elderly subjects ${ }^{18}$. Moreover, we found a strong association between insomnia and positivity in the SRQ. A previous study showed that insomniacs are 35 times more likely to present depression, and 2.7 times more likely to present anxiety ${ }^{4}$. A prospective study showed ${ }^{7}$ that 
medical students who reported having insomnia presented greater risk for clinical depression when compared with those who did not report insomnia. Furthermore, greater clinical depression was found in those with difficulty to sleep under stress compared with those who did not report this difficulty. ${ }^{7}$

In the present study, the presence of difficulty to maintain sleep (MaintS) was associated with a strong probability of having a positive $S R Q$ result $(O R=7.61)$. Frequently, individuals who "wake up during the night after having gone to sleep" do not consider this as a problem, since they are used to a maladaptive sleep pattern. Bonnet underscores the fact that in general, arousal does not result in shortened sleep, but rather in fragmented sleep, and that this fragmentation produces mood disturbances and a decrease in performance ${ }^{19}$. Difficulty to maintain sleep was also the only sleep problem associated with the female gender independently of SRQ levels. Therefore, MaintS may be responsible for the association between insomnia and the female gender. This result, together with the fact that depression and anxiety are more prevalent in women ${ }^{20}$, allows us to hypothesize that sleep fragmentation may be one of the most important variables, among sleep problems, associated to depression and anxiety.

Difficulty to fall asleep at night (InitS) was reported by $17.22 \%$ of the total sample. Subjects with InitS presented an odds ratio of 3.45 for positivity in the SRQ. A high prevalence of InitS has been observed in several cultures; the present relationship between InitS and mental problems is in accordance with other studies that found an association between problems to fall asleep and psychological stress, poor perceived health, and being unable to cope with stress $^{11}$. In the present study, InitS was not significantly associated with gender, which is also consistent with previous findings ${ }^{11}$.

The habit of falling asleep later at night was associated with $S R Q$ positivity $(O R=2)$. Although the cause of this association is not clear, falling asleep later may be (1) associated with delayed sleep phase syndrome; (2) related to shorter sleep duration; (3) only one more symptom of anxiety or depression; or (4) an early symptom of any mental disorder. Changes in sleep pattern appear as a symptom in most psychiatric disorders. Insomnia is especially important in mood disorders, in which it is one of the core diagnostic criteria, and may be an early symptom of depression. In spite of the limitation of a cross-sectional study to determine causality, the association between positivity in the SRQ and insomnia is clear. However, longitudinal studies are required to allow a full understanding of the role of insomnia in mental disorders.

In the present study, men were associated with falling asleep late. Similarly to other differences in gender-related sleep patterns ${ }^{21}$, we believe that the association between male gender and falling asleep later is probably related to sociocultural status. Waking up too early in the morning followed by difficulty to get back to sleep (EMA) did not show association to gender; this result is in accordance with previous research ${ }^{22}$. In the present study, the prevalence of EMA was higher (15.23\%) than in adolescent populations ${ }^{11,22}$. Most probably, differences in the age of the subjects were responsible for these discrepancies, since the prevalence of EMA increases with age ${ }^{11,22}$. When analyzed by univariate analysis, EMA showed a significant association with positivity in the SRQ, but when we controlled the effects of confounding variables by multivariate analysis, the association disappeared. One possibility is that EMA may be a confounding variable for "waking up early," but was corrected by the logistic regression. Waking up before 6 am showed an odds ratio of 1.91 for positivity in the SRQ.

There was no association between "feeling tired during the first hour after waking up" (tiredness) and gender. Moreover, we found an association between tiredness and mental disorder only in the univariate analysis. Similarly, other studies have shown that tiredness could be a consequence of insomnia; according to some studies, this variable is associated with decreased productivity and automobile accidents. ${ }^{3}$. In this study, tiredness and insomnia were analyzed as independent variable by logistic regression. The potential colinearity (i.e. information redundancy) between these variables was checked by likelihood ratio test for determining which variable would be dropped from the model ${ }^{23}$.

In conclusion, the group of variables (InitS, MaintS, falling asleep after $11 \mathrm{pm}$, and waking up before $6 \mathrm{am}$ ) determined an OR of 5.96 for the suspicion of psychiatric disorders, and difficulty to maintain sleep (MaintS) was associated with female gender. Insomnia assessment may be a good tool for the identification of suspected cases of mental disorders in medical students for further diagnostic confirmation and prevention, because early treatment might halt progression to full manifestation of a mental disorder ${ }^{4}$. Moreover, sleep disorders are 
less stigmatizing and easier to discuss during a physician's visit than psychiatric disorders. However, the present findings underscore the importance of determining in what cases difficulty sleeping may have severe clinical repercussions or affect performance and quality of life.

\section{REFERENCES}

1. Roth T, Roehrs, Costa e Silva JA, Chase MH. Public health and insomnia: consensus statement regarding its status and needs for future actions. Sleep 1999;22(Suppl 3):417-s420.

2. Schweitzer PK, Engelhardt CL, Hilliker NA, Muehlbach MJ, Walsh JK. Consequences of reported poor sleep. Sleep Res 1992;21:260.

3. Walsh J, Ustun TB. Prevalence and health consequences of insomnia. Sleep 1999;22(Suppl 3):427-436.

4. Ford DE, Kamerow DB. Epidemiologic study of sleep disturbances and psychiatric disorders: an opportunity for prevention? JAMA 1989;62(Suppl 11):1479-1484.

5. Ohayon MM, Caulet M, Priest RG, Guilleminault C. DSM-IV and Icsd90 insomnia symptoms and sleep dissatisfaction. Br J Psychiatry 1997;171:382-388.

6. Häkkänen H, Summala H. Sleepiness at work among commercial trunk drivers. Sleep 2000;23(Suppl 1):49-57.

7. Chang PP, Ford DE, Mead LA, Cooper-Patrick L, Klag MJ. Insomnia in young men and subsequent depression: the Johns Hookins precursors study. Am J Epidemiol 1997;146:105-114.

8. Daugherty SR, Baldwin DC Jr. Sleep deprivation in senior medical students and first-year residents. Acad Med 1996;71(Suppl 1):93-95.

9. Mari JJ, Williams P. A validity study of a psychiatric screening questionnaire (SRQ-20) in primary care in the city of São Paulo. Br J Psychiatry 1986;148:23-26.
10. Iacoponi E, Mari JJ. Reliability and factor structure of the Portuguese version of self-reporting questionnaire. Int J Soc Psychiatry 1988;35(Suppl 3):213-222.

11. Kim K, Uchiyama M, Okawa M, Liu X, Ogihara R. An epidemiological study of insomnia among the Japanese general population. Sleep 2000;23(Suppl 1):41-47.

12. Fleiss JL. The design and analysis of clinical experiments. New York: John Wiley \& Sons, 1986.

13. Mickey RM, Greenland S. The impact of confounder selection criteria on effect estimation. Am J Epidemiol 1989;129(Suppl 1):125-137.

14. Schlesselman JJ. Assessing effects of confounding variables. Am J Epidemiol 1978;108(Suppl 1):3-8.

15. Norusis M. SPSS-X: advanced statistics guide. Chicago: McGraw Hill, 1985.

16. Dean AG, Dean JA, Burton AH, Dicker RC. Epi Info, Version 5: a word processing, database, and statistics program for epidemiology on $\mathrm{mi}$ cro-computers. Atlanta: Centers for Disease Control, 1990.

17. Feijo RB, Saueressig M, Salazar C, Chaves ML . Mental health screening by self-report questionnaire among community adolescents in southern Brazil. J Adolesc Health 1997;20(Suppl 3):232-237

18. Silberman C, Souza C, Wilhems F, et al. Cognitive deficit and depressive symptoms in a community group of elderly people: a preliminary study. Rev Saude Publica 1995;29(Suppl 5):444-450

19. Bonett MH. The effect of sleep disruption on performance, sleep and mood. Sleep 1985;8:11-19.

20. Almeida N, Mari JJ, Coutinho E, et al. Brazilian multicentric study of psychiatric morbidity. Br J Psychiatry 1997;171:524-529.

21. Lee KA, McEnany G, Weekes D. Gender differences in sleep patterns for early adolescents. J Adolesc Health 1999;24(Suppl 1):16-20.

22. Liu X, Uchiyama M, Okawa M, Kurita H. Prevalence and correlates of self-reported sleep problems among Chinese adolescents. Sleep 2000;23(Suppl 1):27-34.

23. Concato J, Feinstein AR, Holford TRH. The risk of determining risk with multivariable models. Ann Intern Med 1993;118:201-210. 